\title{
Facing Chagas disease
}

\author{
João Carlos Pinto Dias ${ }^{[1],[2]}$
}

[1]. Pesquisador Emérito da Fundação Oswaldo Cruz, Belo Horizonte, MG, Brasil.

[2]. Membro da Academia Mineira de Medicina, Belo Horizonte, MG, Brasil.

April $14^{\text {th }}$ was established as the international day of Chagas disease $(\mathrm{ChD})$ to celebrate the historic discovery of the disease as well as emphasize the need for more effective treatment and management solutions. As stated by Dr. Carlos Chagas, the Brazilian physician and epidemiologist who discovered this disease, $\mathrm{ChD}$ represents a major problem for both the nation and the scientific community, requiring politicians, scientists, and the general population of endemic countries to work together to prevent, manage, and generate social awareness for this disease $\mathrm{e}^{1,2}$.

Since the description of the first human $\mathrm{ChD}$ case in 1909, much progress has been made in the fight against this disease. In parallel, great social transformations have occurred in both endemic and non-endemic regions, such as the urbanization and international migration of affected rural populations, globalization, and the modernization of agriculture. In addition, new insecticides have been created and disease diagnoses have been improved, with novel specific and symptomatic drugs being developed, especially after the 1960-80s when better control of blood banks was implemented and co-infections of $\mathrm{ChD}$ and HIV was detected. Slowly but progressively, the classic vector transmission decreased in endemic areas, predominantly since the 1990s, when intergovernmental programs were launched to combat the proliferation of this disease $^{3,4}$. Regardless, new epidemiological situations and problems continued to occur, including, oral transmissions and the decentralization of health systems. Further, difficulties in production and distribution of therapeutic drugs, lack of medical expertise, and inadequate access to diagnosis and treatment also proved challenging to controlling $\mathrm{ChD}^{3,5}$.

Majority of the $\mathrm{ChD}$ infected individuals belong to an invisible population, meaning they are poor, politically unrepresented, and unillustrated in the consensuses. Thus, $\mathrm{ChD}$ has been considered as a typically neglected disease, which does not usually receive political priority; however, an estimated 8 million individuals are infected worldwide, with the majority unaware that they are infected, leaving approximately 35 million individuals at risk for disease transmission ${ }^{5,6}$.

Over the years, there have been several successes in the fight against $\mathrm{ChD}$, including, reduction of vector transmission

Corresponding author: Dr. João Carlos Pinto Dias.

e-mail: jcpdias@cpqrr.fiocruz.br

Received 14 June 2017

Accepted 14 June 2017 through chemical control and improved housing conditions, screening of blood donors, and advances made in mother-child care (congenital disease) ${ }^{1,3,5}$. Two nitro-heterocyclic drugs (benznidazole and nifurtimox) that have proven to be partially effective for chronic cases can also treat $\mathrm{ChD}^{1,4}$. The fact that Trypanosoma cruzi infects different mammalian species is both a curse and blessing because this parasite will never be eradicated, and thus will always pose a risk to humans. The imminent completion of clinical trials to assess the benefit of treatment with benznidazole during chronic infection in humans should address an enduring question regarding the clinical benefit of treating patients with long-established chronic T. cruzi infections. In addition, human clinical trials investigating new therapies have either progressed or been recently completed ${ }^{1,3,4}$.

It must also be emphasized that, operational and research advances over the last two decades have provided baseline information for improving the detection, prevention, and control of T. cruzi infections. In contrast to long-held views on the autoimmune origin of the ChD's chronic stage pathology, investigation confirms that the persistence of this parasite is the key factor underlying sustained inflammatory responses that lead to these manifestations ${ }^{4}$. Thus, the condition should be treated as an infectious and degenerative - not autoimmune - disease, and specific and symptomatic treatments should be offered to all seropositive patients, perhaps excluding those with terminal disease $\mathrm{e}^{6,7}$. The challenges for sensitive serodiagnosis of $T$. cruzi infections remain unresolved primarily because of challenges associated with accessing and analyzing all of the social and economic characteristics of infected individuals, and the poor diagnostic capabilities of public laboratories. The use of multiple, partially informative tests that ignore discordant samples are not a sustainable and effective way to identify those who need treatment. The mechanism of action of existing treatments is only now being understood ${ }^{1,3,7}$. Novel treatment regimens and combination therapies with drugs available currently, as well as drug candidates with novel mechanisms of action, are being clinically evaluated ${ }^{1,7}$. Studies of the immune response to $T$. cruzi are identifying ways to enhance parasitespecific immune responses in addition to potentially developing vaccines that are more effective in the near future. The lack of medical expertise regarding disease management is another crucial point globally, which presents an additional challenge to the management of this disease in its acute and chronic stages ${ }^{1,3,4}$. 
Politically, there have been some advances in the visibility and control of ChD. Following the launch of national intergovernmental initiatives in 1991, there have been two events that included $\mathrm{ChD}$ in their agendas i.e. the 2010 World Health Organization (WHO) Assembly and the 2015 London Declaration on Neglected Tropical Diseases ${ }^{1,7}$. For $\mathrm{ChD}$, the initial milestones were established primarily by the WHO with a rather limited input from the research community, at-risk communities, patient associations, and healthcare services within endemic countries. The purposes and needs of the original document were?

\section{Purposes:}

- Assess these milestones and address if they can be achieved and if so, how.

- Establish additional milestones when appropriate and document other achievements to date towards these goals.

- Identify the tools, infrastructure, and resources required to achieve the overall goal of effective control of T. cruzi infection by the targeted 2020 date.

\section{Requirements to achieve the goal of controlling ChD by 2020:}

- Maintain and expand the vector control infrastructure, manpower, and expertise in all areas where transmission is occurring. Provide more training opportunities for vector control personnel and achieve high-quality application of insecticides and rigorous evaluation of their impact.

- Design and implement sustainable vector and transmission (including oral, congenital, and transfusion or transplantation) control programs and develop independent assessments to evaluate their efficacy.

- Develop efficient and effective monitoring systems to evaluate vector interventions, including, reservoir community evaluation and vector population dynamics.

- Identify the most common vehicles for oral transmission (how common is oral infection in the household setting, depending on the endemic region?) and develop methods to identify and prevent such transmission (e.g., public health education, facile methods to test for contamination, etc.).

- Institute uniform testing and treatment of adolescents prior to child-bearing years and women of reproductive age, thus reducing opportunities for vertical transmission.

- Facilitate commercialization of high-quality assays for blood and solid organ screening and educate health care professionals to recognize the need to screen solid organ donors as potential sources of infection.

- Combine vector control efforts with treatment and education programs to increase acceptability, coverage, and sustainability.

- Increase access to safe and effective treatments.

- Integrate $\mathrm{ChD}$ into clinical care systems in all countries using workshops, courses, and continuing education, and promote equal access to diagnosis and clinical care.
The declaration emphasizes short-term milestones to focus on obtaining accurate information, developing sound policies, and assuring the ready availably of insecticides, diagnostics, and drugs. Additional appropriate investments and political commitment can translate into actions that will significantly reduce the impact of $\mathrm{ChD}$ by 2020 . As outlined above, this will require a combination of more efficient healthcare systems, information systems, infrastructure (for diagnostic screening, vector control, drug production and distribution, etc.), improved tools (e.g., diagnostic assays, methods to monitor treatment efficacy, etc.), and broader knowledge and a better dialogue with communities, their acceptance of, and collaboration with these projects. Without these developments, it is virtually impossible that any of the proposed 2020 milestones for $\mathrm{ChD}$ in the London Declaration can be met. However, establishing these milestones without a plan to develop appropriate resources is a recipe for failure.

Finally, taking into consideration all the existing technical and political factors for its prevention and medical care, it should be accepted that $\mathrm{ChD}$ is a solvable problem, that dependent on both political will as well as concrete implementation of proposed solutions ${ }^{1,5,6}$.

\section{Conflict of interest}

The author declares that have no conflicts of interest.

\section{REFERENCES}

1. World Health Organization (WHO). Chagas Disease (American trypanosomiasis. Fact sheet updated March 2017. WHO. Geneva: 2017 (Accessed in June 2, 2017).

2. Chagas C. Moléstia de Carlos Chagas ou thyreoidite parasitária. Nova doença humana transmitida pelo "barbeiro" (Conorhynus megistus). Rev Méd S Paulo. 1911;14;337-56.

3. Dias JCP. Enfermedad de Chagas: las etapas recorridas y las perspectivas futuras. In: La enfermedad de Chagas: a la puerta de los 100 años del conocimiento de una endemia americana ancestral. Washington: Organización Panamericana de la Salud. OPS/ Organización Mundo Sano; 2007. p. 37-50.

4. Rassi Jr A, Dias JC, Marin-Neto JA, Rassi A. Challenges and opportunities for primary, secondary, and tertiary prevention of Chagas' disease. Heart. 2009; 95(7):524-34.

5. World Health Organization (WHO). London conference on neglected tropical diseases. WHO. Geneva: 2017. Available from: http://www.unitingtocombatntds.org/. (Accessed in June 1, 2017).

6. Ehrenberg JP, Ault S. Neglected diseases of neglected populations: thinking to reshape the determinants of health in Latin America and the Caribbean. BMC Public Health. 2005;5:119-22.

7. Briceño León R. La enfermedad de Chagas y las transformaciones sociales en América Latina. In: La enfermedad de Chagas a la puerta de los 100 años del conocimiento de una endemia americana ancestral. Washington: Organización Panamericana de la Salud; 2007. p. 219-30. 